\title{
Long-term prognosis of patients with local recurrence after conservative surgery and radiotherapy for early breast cancer
}

\author{
A.C. Voogd ${ }^{\mathrm{a}, *}$, F.J. van Oost ${ }^{\mathrm{b}}$, E.J.T. Rutgers ${ }^{\mathrm{c}}$, P.H.M. Elkhuizen ${ }^{\mathrm{d}}$, A.N. van Geel ${ }^{\mathrm{e}}$, \\ L.J.E.E. Scheijmans ${ }^{f}$, M.J.C. van der Sangen ${ }^{g}$, G. Botke ${ }^{\text {h }}$, C.J. Hoekstra ${ }^{\text {i }}$, J.J. Jobsen ${ }^{j}$, \\ C.J.H. van de Velde ${ }^{\mathrm{k}}$, M.F. von Meyenfeldt ${ }^{1}$, J.M. Tabak ${ }^{\mathrm{m}}$, J.L. Peterse ${ }^{\mathrm{n}}$, \\ M.J. van de Vijver ${ }^{n}$, J.W.W. Coebergh ${ }^{\text {b,o }}$, G. van Tienhoven ${ }^{p}$, \\ for the Dutch Study Group on Local Recurrence after \\ Breast Conservation (BORST Group)
}

\footnotetext{
a Department of Epidemiology, Maastricht University, P.O. Box 616, 6200 MD, Maastricht, The Netherlands

${ }^{\mathrm{b}}$ Comprehensive Cancer Centre South, Eindhoven, The Netherlands

${ }^{\mathrm{c}}$ Department of Surgery, Netherlands Cancer Institute, Amsterdam, The Netherlands

d Department of Radiotherapy, Free University Medical Centre, Amsterdam, The Netherlands

${ }^{\mathrm{e}}$ Department of Surgery, Erasmus Medical CentrelDaniel den Hoed Cancer Centre, Rotterdam, The Netherlands

${ }^{\mathrm{f}}$ Dr. Bernard Verbeeten Institute, Tilburg, The Netherlands

g Department of Radiotherapy, Catharina Hospital, Eindhoven, The Netherlands

${ }^{\mathrm{h}}$ Radiotherapeutisch Instituut Friesland, Leeuwarden, The Netherlands

${ }^{i}$ Radiotherapeutisch Instituut Stedendriehoek, Deventer, The Netherlands

${ }^{\mathrm{j}}$ Medisch Spectrum Twente, Enschede, The Netherlands

${ }^{\mathrm{k}}$ Department of Surgery, Leiden University Medical Centre, Leiden, The Netherlands

${ }^{1}$ Department of Surgery, Academic Hospital Maastricht, The Netherlands

${ }^{\mathrm{m}}$ Zeeuws Radiotherapeutisch Instituut, Vlissingen, The Netherlands

${ }^{n}$ Department of Pathology, Netherlands Cancer Institute, Amsterdam, The Netherlands

${ }^{\circ}$ Erasmus University Medical Centre, Department of Public Health, Rotterdam, The Netherlands

${ }^{\mathrm{p}}$ Department of Radiotherapy, Academic Medical Centre, Amsterdam, The Netherlands
}

Received 9 February 2005; received in revised form 6 April 2005; accepted 8 April 2005 Available online 22 August 2005

\begin{abstract}
We have studied the long-term prognosis of 266 patients considered to have isolated local recurrence in the breast following conservative surgery and radiotherapy for early breast cancer. The median follow-up of the patients still alive after diagnosis of local relapse was 11.2 years. At 10 years from the date of salvage treatment, the overall survival rate for the 226 patients with invasive local recurrence was 39\% $(95 \% \mathrm{CI}, 32-46)$, the distant recurrence-free survival rate was $36 \%(95 \% \mathrm{CI}, 29-42)$, and the local control rate (i.e., survival without subsequent local recurrence or local progression) was 68\% (95\% CI, 62-75). Among patients with a local recurrence at or near the original tumour site a better distant disease-free survival was observed for patients with recurrences measuring $1 \mathrm{~cm}$ or less, compared to those with larger recurrences. This suggests, though does not prove, that early detection of local recurrence can improve the treatment outcome but might as well point towards a different biologic behaviour, facilitating early detection.
\end{abstract}

(C) 2005 Elsevier Ltd. All rights reserved.

Keywords: Breast carcinoma; Breast conservation; Local recurrence; Detection; Survival; Long-term prognosis

\footnotetext{
* Corresponding author. Tel.: +31 43 3882387; fax: +31 433884128.

E-mail address: adri.voogd@epid.unimaas.nl (A.C. Voogd).
} 


\section{Introduction}

It is estimated that each year about 300,000 women with stages I and II breast cancer undergo breast-conserving therapy (BCT) worldwide [1]. Rates of local recurrence in the preserved breast vary between $2 \%$ and $10 \%$ after 5 years and between $5 \%$ and $15 \%$ at 10 years [1-10]. Considering the growing number of patients who have undergone BCT and the risk of local recurrence also extending after more than 10 years of follow-up, the number of patients experiencing a local recurrence is expected to increase considerably in the future.

Whilst the poor prognosis of patients with a local recurrence after modified radical mastectomy is well established, there has been considerable debate about the prognosis and salvage possibilities for patients with local recurrence after BCT. Earlier studies reported 5 -year survival rates ranging from $70 \%$ to $84 \%$ after salvage treatment for patients with local recurrence after $\mathrm{BCT}$, which is equal or only slightly worse compared with those without local recurrence [5,11-13]. More recent series, however, reported poorer 5-year survival rates, ranging from $55 \%$ to $68 \%$ after 5 years $[3,14]$ and one study even reached the conclusion that the survival after treatment for an early loco-regional recurrence after modified radical mastectomy or BCT is similar [15]. The unfavourable prognostic effect of developing a local recurrence has been confirmed by other studies, that included local recurrence in a multivariate analysis as a time-dependent variable and showed it to be a strong independent predictor of the risk of developing distant metastatic disease [6,7,16-21]. Figures on the long-term prognosis of patients with local recurrence are scarce and based on small patient series. Interpretation and comparison of the results is also hampered by heterogeneity; some focused on prognosis after local recurrence treated with salvage mastectomy, whereas others studied prognosis after all local recurrences regardless of therapy. In some studies, patients were included who also had distant metastasis diagnosed before or simultaneously with local recurrence. Finally, studies on prognostic factors for patients with local recurrence made use of different end-points, some presenting overall survival and other distant disease-free or cause-specific survival.

This report describes the long-term prognosis of 266 patients with local recurrence after BCT as first event, i.e., without clinical signs of distant metastases at the time of diagnosis of local recurrence. In a previous report, with a median follow-up time of 52 months, the distant recurrence free survival rate for all 266 patients was $61 \%(95 \% \mathrm{CI}, 40-53 \%)$ at 5 -years from the date of salvage treatment [22]. At that time, the survival curve showed no tendency of levelling off, indicating that distant recurrences continue to occur more than five years after diagnosis of local recurrence. For the current study, the median follow-up of the cohort has been extended to more than 11 years, which offered us the possibility to calculate the survival rates at 10 years after the diagnosis of local recurrence and identify subgroups with a good and a poor long-term prognosis.

\section{Patients and methods}

\subsection{Patients and data collection}

Patient data were obtained from eight departments of radiotherapy, two cancer institutes and one department of surgery in the Netherlands, which maintained complete records on approximately 7000 patients with invasive breast cancer undergoing BCT. BCT generally consisted of wide local excision of the tumour with an attempted margin of at least $1 \mathrm{~cm}$ of healthy tissue and axillary dissection, followed by $45-50 \mathrm{~Gy}$ whole breast irradiation in fractions of 1.8 or 2.0 Gy five times a week. An additional boost was given to the tumour bed by an external beam technique, using either photons or electrons, or by the use of iridium 192 interstitial implants. Total boost doses varied between 15 and $25 \mathrm{~Gy}$ but were sometimes higher for iridium 192 implants. Adjuvant systemic therapy was given only to axillary node-positive patients; in general premenopausal patients received 6 cycles of adjuvant cyclophosphamide, methotrexate and 5-fluorouracil (CMF) combination chemotherapy, given after the completion of radiotherapy, whereas postmenopausal patients received $20 \mathrm{mg}$ of tamoxifen daily for at least 1 year.

Together, the participating centres identified 360 patients with local recurrence after BCT, diagnosed before January 1994. Local recurrence was defined as a new tumour occurring in the preserved breast or overlying skin after complete loco-regional treatment. Of the 360 local recurrences, $28(8 \%)$ were detected after the diagnosis of distant disease, and in $66(18 \%)$ distant disease was diagnosed within three months after the diagnosis of local recurrence. The remaining 266 patients $(74 \%)$ showed no signs of distant metastases or axillary recurrence, at least within the first three months after the diagnosis of local recurrence. These 266 patients were considered to have an 'isolated local recurrence' and constitute the study population. Of these, $248(93 \%)$ had undergone BCT during the 1980s and $18(7 \%)$ during the period 1990-1992. Three patients had not received a boost dose. At initial diagnosis, $150(56 \%)$ had pathological stage I primary breast cancer $\left(\mathrm{T}_{1} \mathrm{~N}_{0} \mathrm{M}_{0}\right), 83$ patients $(31 \%)$ stage IIA $\left(\mathrm{T}_{1} \mathrm{~N}_{1} \mathrm{M}_{0}\right.$, $\left.\mathrm{T}_{2} \mathrm{~N}_{0} \mathrm{M}_{0}\right), 28(11 \%)$ stage IIB $\left(\mathrm{T}_{3} \mathrm{~N}_{0} \mathrm{M}_{0}, \mathrm{~T}_{2} \mathrm{~N}_{1} \mathrm{M}_{0}\right)$ and four $(1 \%)$ stage IIIA $\left(\mathrm{T}_{3} \mathrm{~N}_{1} \mathrm{M}_{0}, \mathrm{~T}_{1-3} \mathrm{~N}_{2} \mathrm{M}_{0}\right)$. Axillary lymph nodes were involved in 71 of the 266 patients $(27 \%)$ at the time of primary treatment. The median age was 45 years (range 16-81 years) at the time of primary 
treatment and 49 years (range 17-82) at diagnosis of the local recurrence. The median time between the date of breast-conservative surgery and diagnosis of local recurrence was 3.6 years (range: $0.3-13.1$ years). Seventy-eight recurrences $(29 \%)$ occurred within two years of BCT, 127 $(48 \%)$ between two and five years, and $61(23 \%)$ more than five years after BCT.

Further details on collection of information on the method of detection and the location, the extent, histologic type and treatment of the local recurrence have been described before [22]. Specimens of the primary tumour were available for review for 238 of the 266 patients $(89 \%)$. Follow-up of the patients was updated until January 2003. The median follow-up time for surviving patients after diagnosis of local recurrence was 134 months.

\subsection{Statistical analysis}

Survival analysis, using the life-table method, was performed to evaluate the prognosis after local recurrence. End-points were overall survival, distant disease-free survival and survival without subsequent local recurrence, including local progression of disease. Survival curves were calculated from the date of salvage treatment of local recurrence or the date of the diagnosis of local recurrence when salvage treatment was not given. The following variables were analysed to assess their ability to predict distant recurrence-free survival: age at diagnosis of local recurrence; time interval from initial surgery to recurrence; mode of detection, location, size and histologic type of local recurrence; size, nodal status, histologic grade and microscopic margins of the original tumour; and presence of vascular invasion and extensive intraductal component (EIC) in the original tumour. Actuarial curves were compared by means of the two-tailed log-rank test. A multivariate analysis using the Cox proportional hazards model was performed to evaluate the independent predictive effect of the covariates. Hazard ratios (with 95\% confidence intervals $(95 \% \mathrm{CI})$ and $P$ values) were estimated for each covariate in relation to the reference category. As the prognostic effect of the co-variates is likely to vary for patients with an early or a late local recurrence, separate analyses were performed for the group with a local recurrence within three years after diagnosis of the primary tumour and the group with a recurrencefree interval of more than three years after BCT.

\section{Results}

\subsection{Diagnosis and treatment}

Local recurrence was diagnosed by mammography alone in 47 cases $(25 \%)$, by physical examination (i.e., on the basis of signs or symptoms) in 102 cases (54\%) and by both physical examination and mammography in 40 cases $(21 \%)$. 225 patients $(85 \%)$ underwent salvage mastectomy and $20(8 \%)$ local excision, $11(4 \%)$ only received systemic treatment and 8 patients $(3 \%)$ remained untreated. Treatment was unknown for one patient. Detailed results on the detection and treatment of LR have been described elsewhere [22].

\subsection{Outcome}

Of the 266 patients with local recurrence, 226 had an invasive and 25 a non-invasive recurrence. Information on the invasiveness of the recurrence was lacking for 15 patients. Of the 226 patients with invasive local recurrence $148(65 \%)$ had died. Distant metastases were observed in 145 patients (64\%) and subsequent local recurrence or local progression in $66(31 \%)$. Of the 145 distant metastases, $88(61 \%)$ were detected within 2.5 years after diagnosis of local recurrence, $126(87 \%)$ occurred within 5 years and $139(96 \%)$ within 10 years. At 10 years from the date of salvage treatment, the overall survival rate for the 226 patients with invasive local recurrence was 39\% (95\% CI, 32-46), the distant recurrence-free survival rate was $36 \%(95 \% \mathrm{CI}, 29-42)$, and the local control rate (i.e., survival without subsequent local recurrence or local progression) was $68 \%(95 \%$ CI, 62-75) (Fig. 1).

Univariate analysis showed the following factors to be significantly associated with the occurrence of distant metastases following an invasive local recurrence: the mode of detection, the type and size of local recurrence, the axillary lymph node status of the primary tumour and the presence of vascular invasion in the primary tumour (Table 1). Patients with a local recurrence that had been detected by mammography alone were less likely to develop distant disease than those with a palpable recurrence $(P=0.038)$. When making a subdivision accord-

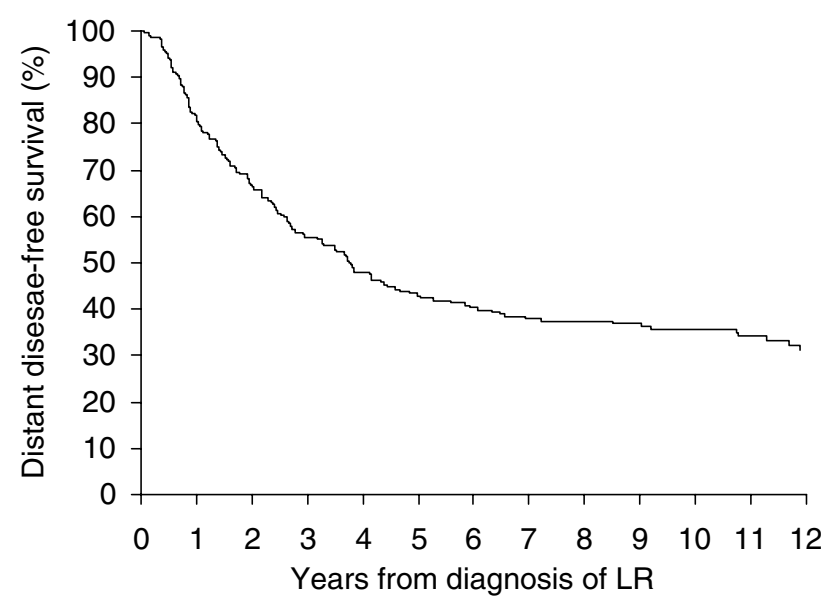

Fig. 1. Distant-recurrence-free survival of 226 patients with invasive local recurrence (LR) following breast-conserving therapy. 
ing to the type and the size of local recurrence, the prognosis of patients with a recurrence elsewhere in the breast appeared to be similar to the prognosis of those with a recurrence of $1 \mathrm{~cm}$ or less located at or near the site of the original tumour and significantly better than the prognosis of the patients with larger recurrences (Fig. 2). A very poor prognosis was observed for patients with a recurrence involving the skin (Fig. 2). The proportion of patients developing distant metastases varied between $62 \%$ and $78 \%$ in the five institutes that contributed at least 25 patients with local recurrence to the study $(P=0.47)$.

Of the 25 patients with a non-invasive recurrence, 4 developed distant metastases and their time to distant disease varied between 53 and 79 months.

The results of the multivariate Cox regression analyses of prognostic factors for distant recurrence-free survival, overall survival and local control are presented in Table 2.

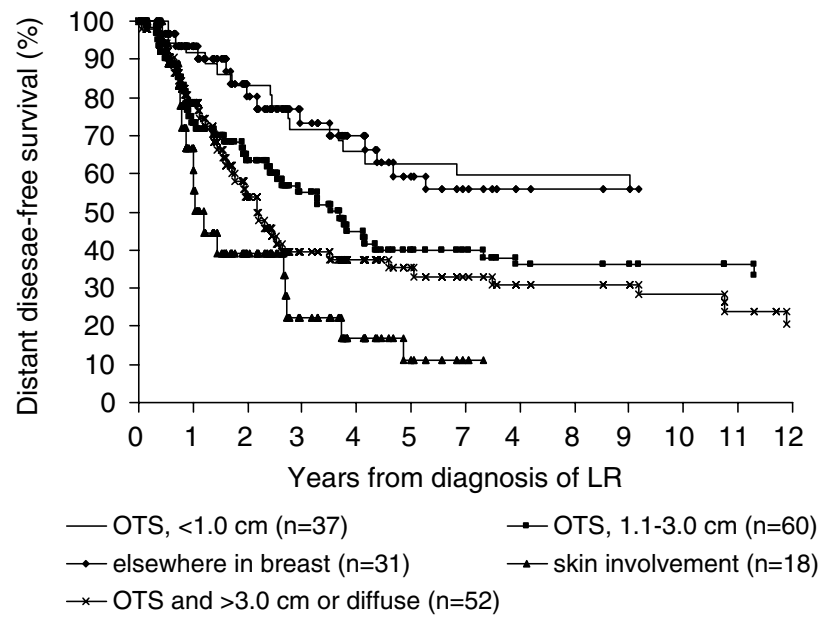

Fig. 2. Distant-recurrence-free survival of 226 patients with invasive local recurrence (LR) following breast-conserving therapy, according to the type of LR (OTS: at or near the original tumour site).

Table 1

Univariate analysis of factors related to distant recurrence in patients with invasive local recurrence after breast-conserving therapy $(n=226)$

\begin{tabular}{|c|c|c|c|c|}
\hline \multirow[t]{2}{*}{ Variable } & \multirow[t]{2}{*}{ No. of patients } & \multicolumn{3}{|c|}{ Distant recurrence-free survival } \\
\hline & & No. & Five-year actuarial rate (SE) & $P$-value (log-rank) \\
\hline \multicolumn{5}{|l|}{ Age at diagnosis of LR (years) } \\
\hline$<45$ & 81 & 56 & $43(5)$ & \multirow[t]{3}{*}{0.405} \\
\hline $45-64$ & 121 & 75 & $49(4)$ & \\
\hline$\geq 65$ & 24 & 14 & $55(9)$ & \\
\hline \multicolumn{5}{|l|}{ Time interval to LR (years) } \\
\hline$\leq 2.0$ & 68 & 45 & $43(6)$ & \multirow[t]{3}{*}{0.746} \\
\hline $2.1-5.0$ & 107 & 69 & $39(5)$ & \\
\hline$>5.0$ & 51 & 31 & $53(7)$ & \\
\hline \multicolumn{5}{|l|}{ Mode of detection of $L R$} \\
\hline Mammography alone & 38 & 20 & $58(8)$ & \multirow[t]{2}{*}{0.038} \\
\hline Signs and symptoms & 125 & 85 & $36(4)$ & \\
\hline \multicolumn{5}{|l|}{ Type of $L R$} \\
\hline At or near OTS and $\leq 1.0 \mathrm{~cm}$ & 37 & 15 & $63(8)$ & \multirow[t]{5}{*}{$<0.0001$} \\
\hline At or near OTS and $1.1-3.0 \mathrm{~cm}$ & 60 & 40 & $40(6)$ & \\
\hline Elsewhere in breast & 31 & 14 & $60(9)$ & \\
\hline At or near OTS and $>3.0 \mathrm{~cm}$ or diffuse & 52 & 38 & $35(7)$ & \\
\hline Skin involvement & 18 & 17 & $11(7)$ & \\
\hline \multicolumn{5}{|l|}{ Lymph node status of primary tumour } \\
\hline Negative & 173 & 105 & $48(4)$ & \multirow[t]{2}{*}{0.020} \\
\hline Positive & 53 & 40 & $29(6)$ & \\
\hline \multicolumn{5}{|l|}{ Size primary tumour $(\mathrm{cm})$} \\
\hline$\leq 2.0$ & 169 & 109 & $44(4)$ & \multirow[t]{2}{*}{0.997} \\
\hline$>2.0$ & 55 & 34 & $42(7)$ & \\
\hline \multicolumn{5}{|l|}{ Vascular invasion (primary) } \\
\hline No & 131 & 85 & $50(4)$ & \multirow[t]{2}{*}{0.017} \\
\hline Yes & 55 & 48 & $33(6)$ & \\
\hline \multicolumn{5}{|l|}{ Extensive intraductal component (primary) } \\
\hline No & 149 & 91 & $43(4)$ & \multirow{2}{*}{0.857} \\
\hline Yes & 49 & 34 & $51(7)$ & \\
\hline \multicolumn{5}{|l|}{ Histologic grade (primary) } \\
\hline Low/intermediate & 90 & 53 & $49(6)$ & \multirow[t]{2}{*}{0.339} \\
\hline High & 120 & 72 & $43(5)$ & \\
\hline
\end{tabular}


Table 2

Cox regression analysis: distant recurrence, death, and subsequent local recurrence (LR) or local progression

\begin{tabular}{|c|c|c|c|c|c|c|c|c|c|}
\hline \multirow[t]{2}{*}{ Variable } & \multicolumn{3}{|c|}{ Distant recurrence } & \multicolumn{3}{|l|}{ Death } & \multicolumn{3}{|c|}{$\begin{array}{l}\text { Subsequent LR or local } \\
\text { progression }\end{array}$} \\
\hline & HR & $95 \% \mathrm{CI}$ & $P$-value & HR & $95 \% \mathrm{CI}$ & $P$-value & HR & $95 \% \mathrm{CI}$ & $P$-value \\
\hline \multicolumn{10}{|l|}{ Type of $L R$} \\
\hline At or near OTS and $\leq 1.0 \mathrm{~cm}$ & 1 (Ref) & & & 1 (Ref) & & & 1 (Ref) & & \\
\hline At or near OTS and $1.1-3.0 \mathrm{~cm}$ & 1.86 & $1.15-3.00$ & 0.012 & 1.70 & $1.06-2.74$ & 0.028 & 1.56 & $0.73-3.32$ & 0.247 \\
\hline At or near OTS and $>3.0 \mathrm{~cm}$ or diffuse & 2.53 & $1.55-4.15$ & 0.0002 & 2.39 & $1.49-3.83$ & 0.0003 & 2.17 & $1.23-3.82$ & 0.007 \\
\hline Elsewhere in breast & 1.04 & $0.49-2.19$ & 0.218 & 0.90 & $1.30-6.03$ & 0.775 & 1.52 & $0.48-4.81$ & 0.478 \\
\hline Skin involvement & 4.24 & $2.30-7.82$ & $<0.0001$ & 5.89 & $3.24-10.73$ & $<0.0001$ & 3. 56 & $1.67-7.63$ & 0.001 \\
\hline \multicolumn{10}{|l|}{ Lymph node status of primary tumour } \\
\hline Negative & 1 (Ref) & & & 1 (Ref) & & & $1(\mathrm{Ref})$ & & \\
\hline Positive & 1.70 & $1.14-2.54$ & 0.010 & 1.96 & $1.32-2.92$ & 0.0009 & 1.68 & $0.94-2.99$ & 0.08 \\
\hline
\end{tabular}

HR: hazard ratio; OTS: original tumour site; CI: confidence interval.

The following variables were included in the multivariate model: age at diagnosis of local recurrence, time interval to local recurrence, type of local recurrence and lymph node status and size of the primary tumour. Due to missing information on one or more of these variables, 30 patients had to be excluded from the multivariate analyses. The prognosis of these patients with respect to the three end-points appeared to be similar to the prognosis for the 196 left for the multivariate model, indicating that there was not a selective drop-out of patients from the multivariate analysis. The results of the multivariate analyses showed only slight differences with respect to the three end-points. Patients with positive axillary lymph nodes at the time of diagnosis of the primary tumour had a significantly higher risk of dying or developing distant disease, compared to patients with a negative lymph node status. Patients with a local recurrence at or near the original tumour site measuring $1.0 \mathrm{~cm}$ or less had a lower risk of dying or developing distant disease compared to patients with a larger recurrence. Skin involvement of local recurrence was the strongest prognostic factor for the occurrence of distant disease, subsequent local recurrence or local progression and for death. Adding vascular invasion and mode of detection to the model significantly lowered the statistical power of the model without improving its prognostic value.

Multivariate analyses were also performed according to the time to recurrence (Table 3 ). A positive lymph node status of the primary tumour was significantly associated with an increased risk of developing distant disease in patients with a local recurrence within three years after BCT but not for patients with a local recurrence more than three years after BCT. For both early and late recurrences, a larger diameter and involvement of the skin were unfavourable prognostic factors, although the effect of the skin involvement was only statistically significant for the early recurrences.

\section{Discussion}

The current study is one of the largest describing the long-term prognosis of patients with recurrence in the

Table 3

Cox regression analysis: distant recurrence, according to the time interval between the diagnosis of the primary tumour and the diagnosis of local recurrence

\begin{tabular}{|c|c|c|c|c|c|c|}
\hline \multirow[t]{3}{*}{ Variable } & \multicolumn{6}{|c|}{ Time interval between primary tumour and local recurrence } \\
\hline & \multicolumn{3}{|c|}{$<=3.0$ years } & \multicolumn{3}{|c|}{$>3.0$ years } \\
\hline & HR & $95 \% \mathrm{CI}$ & $P$-value & HR & $95 \% \mathrm{CI}$ & $P$-value \\
\hline \multicolumn{7}{|l|}{ Type of $L R$} \\
\hline At or near OTS and $\leq 1.0 \mathrm{~cm}$ & 1 (Ref) & & & $1(\mathrm{Ref})$ & & \\
\hline At or near OTS and $1.1-3.0 \mathrm{~cm}$ & 1.83 & $0.88-3.81$ & 0.109 & 1.93 & $1.06-3.50$ & 0.032 \\
\hline At or near OTS and $>3.0 \mathrm{~cm}$ or diffuse & 1.92 & $1.06-3.48$ & 0.032 & 2.32 & $1.19-4.52$ & 0.014 \\
\hline Elsewhere in breast & 0.62 & $0.18-2.10$ & 0.443 & 1.53 & $0.52-4.50$ & 0.441 \\
\hline Skin involvement & 3.34 & $1.67-6.71$ & 0.0007 & 2.74 & $0.90-8.32$ & 0.075 \\
\hline \multicolumn{7}{|l|}{ Lymph node status of primary tumour } \\
\hline Negative & 1 (Ref) & & & $1($ Ref) & & \\
\hline Positive & 1.88 & $1.05-3.34$ & 0.033 & 1.20 & $0.64-2.25$ & 0.578 \\
\hline
\end{tabular}

HR: hazard ratio; OTS: original tumour site; CI: confidence interval. 
treated breast following BCT and indicates that about two third ultimately develops distant metastases. Not only the site of the recurrence but also its size provided important information about the risk of developing distant disease. Patients with recurrences $\leqslant 1 \mathrm{~cm}$ had a lower distant recurrence risk compared to patients with local recurrences $>1 \mathrm{~cm}$. Although this seems to point towards a potential benefit of early detection of local recurrence, it can also be explained by a different biological behaviour, associated with certain clinical and mammographic features that facilitate detection. Prognostic factors were almost similar for patients with a local recurrence within three years after diagnosis of the primary tumour and the group with a recurrence-free interval of more than three years, except for the axillary nodal status of the primary tumour that was only of importance for the first group.

Many studies have been performed to distinguish the local recurrences associated with a good or a poor prognosis and to identify risk factors for the development of distant metastases. The question is whether salvage mastectomy is sufficient treatment or should it be followed by systemic treatment, depending on the risk for distant relapse? There is currently no good evidence that adjuvant systemic treatment is effective in patients with local recurrence. In a recent Cochrane systematic review of three randomised-controlled trials comparing systemic therapy versus observation for women with loco-regional recurrence following mastectomy or breast-conserving treatment who did not have previous or synchronous distant metastases, provided insufficient evidence for an improvement in the overall survival [23]. However, when overlooking the available evidence for its effectiveness in primary breast cancer, it is our opinion that adjuvant systemic (re-)treatment should be considered in patients with unfavourable prognostic factors. Local recurrence at or near the site of the original tumour [22,24-26], skin involvement [22,27], diffuse growth of recurrence [22,24], a short disease-free interval $[3,4,8,12,13,15,20,28-30]$ and an unfavourable initial tumour stage $[22,31]$ have been found to be predictors of a poorer prognosis in more than one study. Patients with a recurrence remote from the primary tumour appear to have a better prognosis than those with a recurrence at or near the site of the primary tumour $[22,24-26]$. The most likely explanation for this finding is that the first group consists largely of new primary tumours, whereas the recurrences that are located at or near the site of the primary tumour are true recurrences, originating from tumour tissue not removed by the primary excision. In the literature on the subject of local recurrence, the entities 'new primary tumour' and 'true recurrence' play an important role. The distinction between a true recurrence and a new primary is not always a clear-cut case. In most studies, the diagnosis 'new primary' was applied when the recurrence was located elsewhere in the breast, had a dif- ferent histology, or DNA flow cytometry converted from an aneuploid primary to a diploid recurrence $[14,25,26]$. In the search for reliable distinction between new primary tumours and true recurrences, genetic techniques have been developed [32,33]. Schlechter [33] recently described a quantitative scoring system based on so-called allele imbalance (AI) or loss of heterozygosity ( $\mathrm{LOH})$. These DNA abnormalities, that are present in nearly all breast cancers, are traceable in archival specimens. They concluded that their approach is a potentially valuable tool in distinguishing new primary cancer from true recurrent disease, but further testing with a larger sample size is necessary to draw conclusions about the potential prognostic and therapeutic value of this technique.

In many studies, patients with a local recurrence within two or three years after the original treatment appeared to have a poorer overall and distant disease-free survival compared to those with a local recurrence occurring later $[3,4,8,12,13,15,20,28-30]$. True recurrences tend to have a shorter interval from BCT than the recurrences that are considered to be new primary tumours. This may explain why the proportion of patients with new primary tumours is generally larger in studies with longer follow-up after BCT and why the late recurrences are reported to have a better prognosis than the early recurrences. In our study the prognosis for patients with a local recurrence more than two years after BCT was similar to that for patients with a local recurrence within two years, which is in agreement with some other studies $[31,34]$. The number of patients with a recurrence more than five years after BCT was too small to estimate their prognosis accurately.

Hardly any study is available that performed a review of the histology slides of the local recurrence to identify prognostic factors [30,35]. In a series of 38 patients, DNA ploidy and S-phase fraction as measured by flow-cytometry techniques, showed some promising results as a tool in determining prognosis [35]. In another study of 68 patients, a high mitotic count was found to be associated with a higher risk of distant metastases [30].

Overall and distant recurrence-free survival and local control of disease were very poor for patients with recurrence in the skin of the breast, which was in accordance with the findings of Gage [27]. Such recurrences are likely to be markers of the metastatic potential of the tumour.

Although the 25 patients with a purely non-invasive local recurrence had a much better prognosis than the 225 with an invasive recurrence, distant metastases occurred in four of them. This is high risk when compared to patients with primary non-invasive breast cancer and suggests that the force of mortality remains present from the primary invasive cancer. In contrast to patients with invasive recurrences all distant metastases became clinically apparent more than four years after diagnosis of the local recurrence. 
Finally, the prognosis of patients with a local recurrence also tends to be related to the risk of local recurrence as such. This observation comes from the patients undergoing breast-conserving surgery without radiotherapy; the high risk of local recurrence within this group is accompanied with a significantly better breast-cancer-specific survival following the diagnosis of local recurrence compared to the patients with local recurrence following breast-conserving surgery with radiotherapy [3].

In our large and unselected series of patients with local recurrence following conservative surgery and radiotherapy, long-term prognosis was poor, with a 10 -year distant disease-free survival of only $36 \%$. Lymph node status at the time of diagnosis of the primary tumour and location and size of breast cancer recurrence are predictors of this outcome. Although the latter finding suggests that followup directed at early detection of local recurrences might be worthwhile, it would require a large randomised study, comparing follow-up strategies with differing intensities, to confirm this.

\section{Conflict of interest}

None to declare.

\section{References}

1. Veronesi U, Cascinelli N, Mariani L, et al. Twenty-year follow-up of a randomized study comparing breast-conserving surgery with radical mastectomy for early breast cancer. N Engl J Med 2002, 347(16), 1227-1232.

2. Arriagada R, Le MG, Guinebretiere JM, et al. Late local recurrences in a randomised trial comparing conservative treatment with total mastectomy in early breast cancer patients. Ann Oncol 2003, 14(11), 1617-1622.

3. Fredriksson I, Liljegren G, Arnesson L, et al. Local recurrence in the breast after conservative surgery-a study of prognosis and prognostic factors in 391 women. Eur J Cancer 2002, 38(14), 1860

4. Fourquet A, Campana F, Zafrani B, et al. Prognostic factors of breast recurrence in the conservative management of early breast cancer: a 25-year follow-up. Int J Radiat Oncol Biol Phys 1989, 17(4), 719-725.

5. Kurtz JM, Amalric R, Brandone $\mathrm{H}$, et al. Local recurrence after breast-conserving surgery and radiotherapy. Frequency, time course, and prognosis. Cancer 1989, 63(10), 1912-1917.

6. Elkhuizen $\mathrm{PH}$, van de Vijver MJ, Hermans $\mathrm{J}$, et al. Local recurrence after breast-conserving therapy for invasive breast cancer: high incidence in young patients and association with poor survival. Int J Radiat Oncol Biol Phys 1998, 40(4), 859-867.

7. Kemperman H, Borger J, Hart A, et al. Prognostic factors for survival after breast conserving therapy for stage I and II breast cancer. The role of local recurrence. Eur J Cancer 1995, 31A(5), 690-698.

8. Krauss DJ, Kestin LL, Mitchell C, et al. Changes in temporal patterns of local failure after breast-conserving therapy and their prognostic implications. Int J Radiat Oncol Biol Phys 2004, 60(3), $731-740$.
9. Fisher B, Jeong JH, Anderson S, et al. Twenty-five-year follow-up of a randomized trial comparing radical mastectomy, total mastectomy, and total mastectomy followed by irradiation. $N$ Engl J Med 2002, 347(8), 567-575.

10. van Dongen JA, Voogd AC, Fentiman IS, et al. Long-term results of a randomized trial comparing breast-conserving therapy with mastectomy: European Organization for Research and Treatment of Cancer 10801 trial. J Natl Cancer Inst 2000, 92(14), 1143-1150.

11. Clark RM, Wilkinson RH, Mahoney LJ, et al. Breast cancer: a 21 year experience with conservative surgery and radiation. Int $J$ Radiat Oncol Biol Phys 1982, 8(6), 967-979.

12. Clarke DH, Le MG, Sarrazin D, et al. Analysis of local-regional relapses in patients with early breast cancers treated by excision and radiotherapy: experience of the Institut Gustave-Roussy. Int $J$ Radiat Oncol Biol Phys 1985, 11(1), 137-145.

13. Calle R, Vilcoq JR, Zafrani B, et al. Local control and survival of breast cancer treated by limited surgery followed by irradiation. Int J Radiat Oncol Biol Phys 1986, 12(6), 873-878.

14. Haffty BG, Carter D, Flynn SD, et al. Local recurrence versus new primary: clinical analysis of 82 breast relapses and potential applications for genetic fingerprinting. Int $J$ Radiat Oncol Biol Phys 1993, 27(3), 575-583.

15. van Tienhoven G, Voogd AC, Peterse JL, et al. Prognosis after treatment for loco-regional recurrence after mastectomy or breast conserving therapy in two randomised trials (EORTC 10801 and DBCG-82TM). EORTC Breast Cancer Cooperative Group and the Danish Breast Cancer Cooperative Group. Eur J Cancer 1999, 35(1), 32-38.

16. Fisher B, Anderson S, Fisher ER, et al. Significance of ipsilateral breast tumour recurrence after lumpectomy. Lancet 1991, 338(8763), 327-331.

17. Whelan T, Clark R, Roberts R, et al. Ipsilateral breast tumor recurrence postlumpectomy is predictive of subsequent mortality: results from a randomized trial. Investigators of the Ontario Clinical Oncology Group. Int J Radiat Oncol Biol Phys 1994, 30(1), 11-16.

18. Veronesi U, Marubini E, Del Vecchio M, et al. Local recurrences and distant metastases after conservative breast cancer treatments: partly independent events. J Natl Cancer Inst 1995, 87(1), 19-27.

19. Francis M, Cakir B, Ung O, et al. Prognosis after breast recurrence following conservative surgery and radiotherapy in patients with node-negative breast cancer. Br J Surg 1999, 86(12), 1556-1562.

20. Haffty BG, Reiss M, Beinfield M, et al. Ipsilateral breast tumor recurrence as a predictor of distant disease: implications for systemic therapy at the time of local relapse. J Clin Oncol 1996, 14(1), 52-57.

21. Fortin A, Larochelle $\mathrm{M}$, Laverdiere $\mathrm{J}$, et al. Local failure is responsible for the decrease in survival for patients with breast cancer treated with conservative surgery and postoperative radiotherapy. J Clin Oncol 1999, 17(1), 101-109.

22. Voogd AC, van Tienhoven G, Peterse HL, et al. Local recurrence after breast conservation therapy for early stage breast carcinoma: detection, treatment, and outcome in 266 patients. Dutch Study Group on Local Recurrence after Breast Conservation (BORST). Cancer 1999, 85(2), 437-446.

23. Rauschecker H, Clarke M, Gatzemeier W, et al. Systemic therapy for treating locoregional recurrence in women with breast cancer. Cochrane Database Syst Rev(4)., CD002195.

24. Haffty BG, Fischer D, Beinfield M, et al. Prognosis following local recurrence in the conservatively treated breast cancer patient. Int J Radiat Oncol Biol Phys 1991, 21(2), 293-298.

25. Huang E, Buchholz TA, Meric F, et al. Classifying local disease recurrences after breast conservation therapy based on location and histology: new primary tumors have more favorable outcomes than true local disease recurrences. Cancer 2002, 95(10), 2059-2067. 
26. Smith TE, Lee D, Turner BC, et al. True recurrence vs. new primary ipsilateral breast tumor relapse: an analysis of clinical and pathologic differences and their implications in natural history, prognoses, and therapeutic management. Int J Radiat Oncol Biol Phys 2000, 48(5), 1281-1289.

27. Gage I, Schnitt SJ, Recht A, et al. Skin recurrences after breastconserving therapy for early-stage breast cancer. J Clin Oncol 1998, 16(2), 480-486.

28. Kurtz JM, Spitalier JM, Amalric R, et al. The prognostic significance of late local recurrence after breast-conserving therapy. Int J Radiat Oncol Biol Phys 1990, 18(1), 87-93.

29. Le MG, Arriagada R, Spielmann M, et al. Prognostic factors for death after an isolated local recurrence in patients with early-stage breast carcinoma. Cancer 2002, 94(11), 2813-2820.

30. Elkhuizen PH, Hermans J, Leer JW, et al. Isolated late local recurrences with high mitotic count and early local recurrences following breast-conserving therapy are associated with increased risk on distant metastasis. Int J Radiat Oncol Biol Phys 2001, 50(2), 387-396.
31. Fowble B, Solin LJ, Schultz DJ, et al. Breast recurrence following conservative surgery and radiation: patterns of failure, prognosis, and pathologic findings from mastectomy specimens with implications for treatment. Int J Radiat Oncol Biol Phys 1990, 19(4), 833-842.

32. Regitnig $\mathrm{P}$, Moser $\mathrm{R}$, Thalhammer $\mathrm{M}$, et al. Microsatellite analysis of breast carcinoma and corresponding local recurrences. J Pathol 2002, 198(2), 190-197.

33. Schlechter BL, Yang Q, Larson PS, et al. Quantitative DNA fingerprinting may distinguish new primary breast cancer from disease recurrence. $J$ Clin Oncol 2004, 22(10), $1830-1838$

34. Abner AL, Recht A, Eberlein T, et al. Prognosis following salvage mastectomy for recurrence in the breast after conservative surgery and radiation therapy for early-stage breast cancer. $J$ Clin Oncol 1993, 11(1), 44-48.

35. Haffty BG, Toth M, Flynn S, et al. Prognostic value of DNA flow cytometry in the locally recurrent, conservatively treated breast cancer patient. J Clin Oncol 1992, 10(12), 1839-1847. 